\title{
The Zograscope-A Forgotten Name in Optics
}

\author{
By J. A. Chaldecott, M.Sc., A.Inst.P.
}

(Assistant Keeper, Science Museum)

\section{$A B S T R A C T$ of Paper read on 23rd February, 1953}

In 1735 George Adams (the Elder) set up as an instrument maker at Tycho Brahe's Head in Fleet Street where, following his death in 1773, the business was subsequently carried on by his first son, George Adams (the Younger), until the latter's death in 1795. Both men became well-known instrument makers and both in turn were appointed Mathematical Instrument Maker to King George III. In addition to making scientific instruments, however, these two men also wrote a number of works on subjects connected with the use of such instruments, and some of these books proved sufficiently popular to justify the publication of reprints and, later still, of revised editions. Many of these books contain catalogues listing instruments made and sold by G. Adams in Fleet Street, and it is from an examination of these catalogues that we find references to a name long since forgotten in the realm of optics -the zograscope.

The first mention of this name occurs in the catalogue bound at the end of the elder George Adams' The Description and Use of the Universal Trigonometrical Octant, London, 1753, where there is an entry: "ZOGRASCOPES for viewing Perspective Prints". Similarly worded entries are also to be found in three other works published by the same author between 1766 and 1771 , the prices charged for such instruments ranging from $18 \mathrm{~s}$. to $£ 212 \mathrm{~s}$. 6d. Such entries are not to be found in catalogues bound with the works of the younger George Adams, nor does the term "zograscope" occur elsewhere in the scientific literature of the period. Some years later, however, in the younger George Adams' An Essay on Vision, London, 1789, there appeared the following entry: "Optical machines for viewing perspective prints from

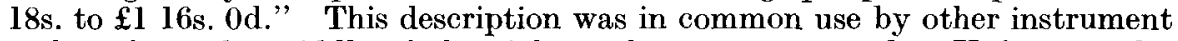
makers from the middle of the eighteenth century onwards. Unfortunately, neither of the two George Adams nor others of the period gave an illustration of the instrument called by the appropriate name, but in view of the similar purpose and corresponding price ranges quoted, there seems every likelihood that both descriptions did in fact apply to the same instrument.

After the death of the younger George Adams, his books and instruments were sold by auction, the stock and copyright of the books being purchased by the brothers W. \& S. Jones. These brothers continued to make instruments to the Adams' design for some years thereafter, and W. Jones also published revised editions of Adams' works. From catalogues of W. \& S. Jones, bound with these revised editions, we find that in 1797 these brothers were making "Optical diagonal machines for viewing prints" at a selling price ranging from $£ 1$ to $£ 11 \mathrm{ls}$. $6 \mathrm{~d}$. In addition, they also advertised "Perspective views in great variety for ditto, each 1s. 6d."

The manufacture of optical diagonal machines was continued by W. \& S. Jones for at least another sixteen years after 1797, and other scientific instrument makers listed them in their trade advertisements and catalogues until as late as 1885. An illustration of an "Optical Diagonal Mirror, for viewing prints in perspective" appears in An lllustrated and Descriptive Catalogue of Surveying, Philosophical . . . Instruments Manufactured by L. Casella, which was published in London in 1871 (see figure 1). The instrument depicted is almost identical with one that has recently come into the possession of the 


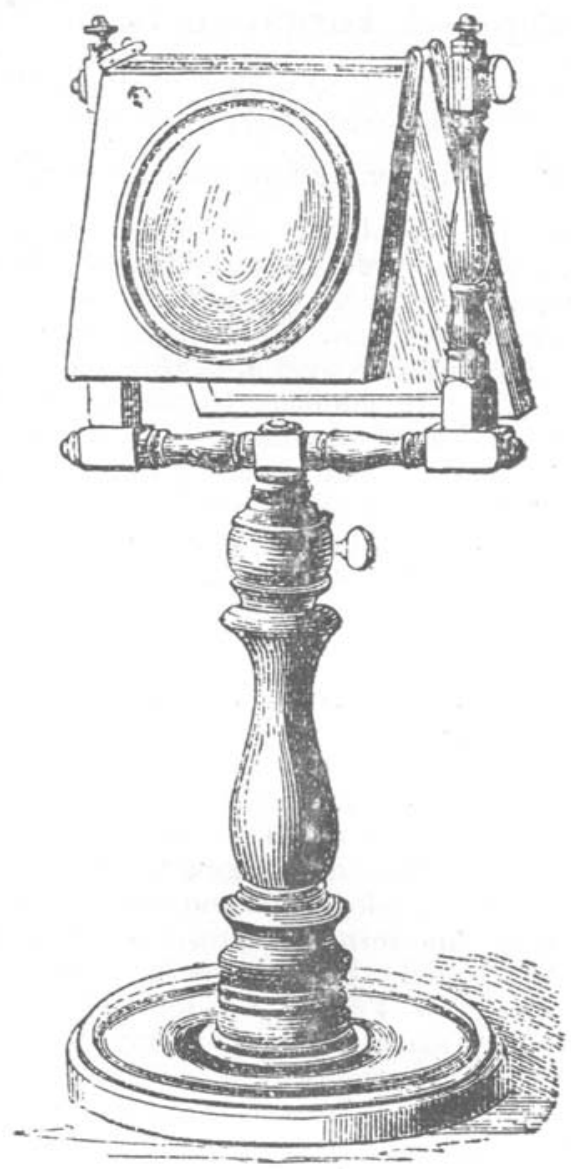

Figure 1. Optical diagonal mirror from catalogue of 1871 . ( Reproduced by courtesy of C. F. Casella \& Co. Ltrl.)

Science Museum still bearing the trade label on which is printed :

$$
\text { Made by }
$$

Edwd. Natrene

Optical \& Mathematical Instrument Maker

To His MaJesty

No. 20, Opposite the Royal Exchange

CORNHILL, LONDON

This Nairne instrument was probably made between 1745 and 1765 . It consists of a double-convex lens, aperture $4 \frac{1}{4}$ inches and focal length about $24 \frac{1}{2}$ inches, mounted in a square inlaid frame of mahogany to which is hinged along the top another frame carrying a rectangular plane mirror $7 \frac{1}{2}$ inches long by $5 \frac{1}{2}$ inches wide. This mirror can be clamped at any inclination to the horizontal and in all settings the lens hangs vertically.

In use the instrument is supported on a table and a perspective print placed in a horizontal position near the base. The height of the optical system above the base may then be adjusted so that the print is located near the focal 


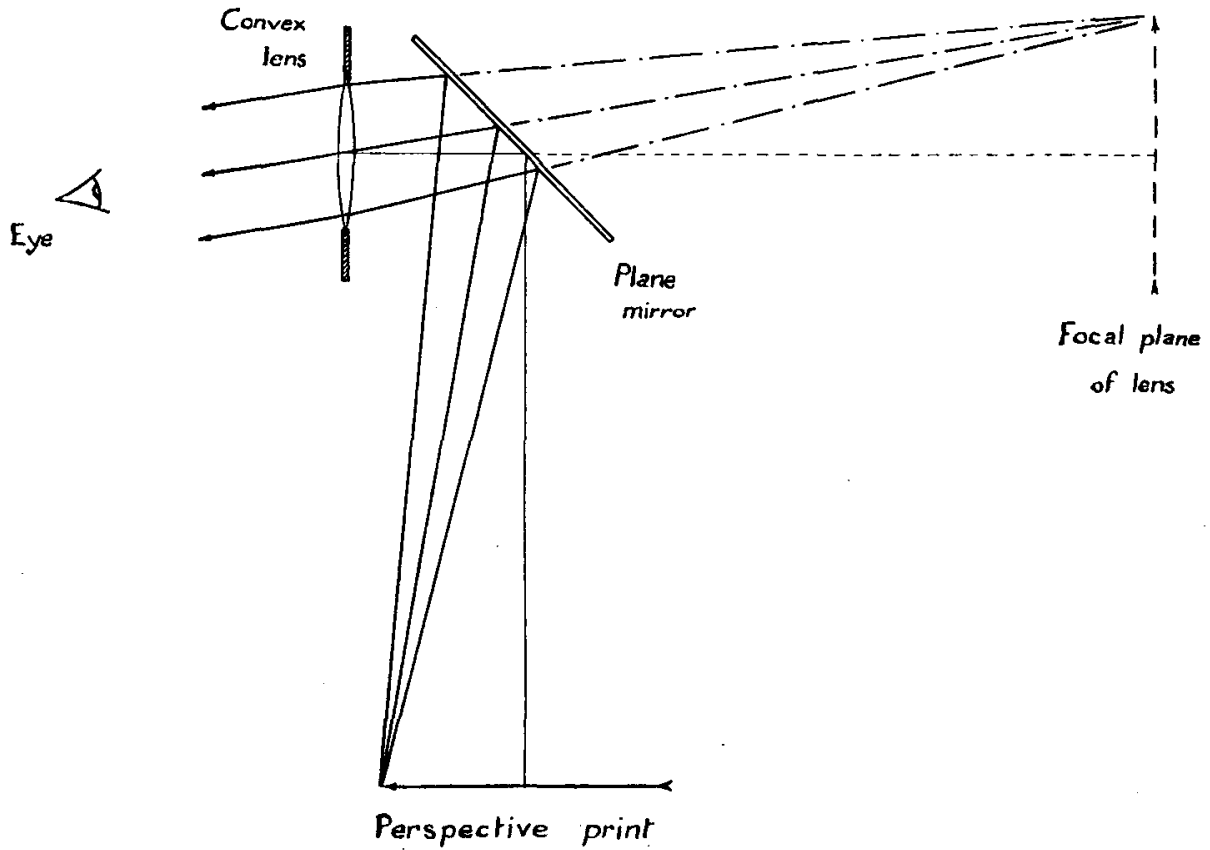

Figure 2. Ray diagram showing zograscope used to produce greatly enlarged image of perspective print.

plane of the lens as reflected by the mirror. Under these circumstances, when the perspective print is examined by looking through the lens, a vertical view is obtained with the details of the picture apparently situated at a considerable distance from the observer. The optical ray diagram for such an arrangement is shown in figure 2 .

It has been suggested that devices of this kind date from about the beginning of the eighteenth century, possibly originating in France where they were known by name "optique". During that century, as the result of a custom that had spread from France, it was no longer considered fashionable to wear spectacles in society, and older people suffering from presbyopia were thus unable to examine the fine detail of copperplate engravings, in public at any rate. The use of the zograscope, or optical diagonal machine, would be of great assistance to such people since the magnified image produced by such an instrument is thrown well back beyond the observer's nearest point of distinct vision.

The incorporation of a plane mirror in the optical design of these instruments made it necessary for the perspective prints intended for use therewith to have a left-to-right reversal of details in order that these should be seen in their true relative positions when viewed through the instrument. In well-preserved prints this lateral reversal is most easily recognized by the presence, on the upper margin of the print, of a title printed in mirrorreversed letters. No doubt large numbers of these prints were prepared, but they are not always easy to come by in this country at the present time. Two examples have recently been acquired by the Science Museum, however, one being dated 1753 whilst the other probably belongs to a somewhat earlier period, possibly about 1710 . 